\title{
Modal and Vibration Analysis of Filter System in Petrochemical Plant
}

\author{
Zhongchi Liu, ${ }^{1}$ Ji Wang, ${ }^{2,3}$ Wie Min Gho, ${ }^{4}$ Xiao Liu, ${ }^{3}$ and Xuebing Yu${ }^{1}$ \\ ${ }^{1}$ Institute of Internal Combustion Engine, Dalian University of Technology, Dalian, China \\ ${ }^{2}$ Collaborative Innovation Center for Advanced Ship and Deep-Sea Exploration, Dalian, China \\ ${ }^{3}$ School of Naval Architecture \& Ocean Engineering, Dalian University of Technology, Dalian, China \\ ${ }^{4}$ Maritime Research Centre and School of Civil and Environmental Engineering, Nanyang Technological University, Singapore \\ Correspondence should be addressed to Ji Wang; wangji@dlut.edu.cn
}

Received 17 March 2017; Revised 22 June 2017; Accepted 13 July 2017; Published 22 August 2017

Academic Editor: Hugo Rodrigues

Copyright (c) 2017 Zhongchi Liu et al. This is an open access article distributed under the Creative Commons Attribution License, which permits unrestricted use, distribution, and reproduction in any medium, provided the original work is properly cited.

\begin{abstract}
Filter systems are widely used in petrochemical plants for removing solid impurities from hydrocarbon oils. The backwash is the cleaning process used to remove the impurities on the sieves of the filters without a need to interrupt the operation of the entire system. This paper presents a case study based on the actual project of a filter system in a petrochemical plant, to demonstrate the significant effect of vibration on the structural integrity of piping. The induced vibration had led to the structural fatigue failure of the pipes connecting the filter system. A preliminary assessment suggested that the vibrations are caused by the operation of backwashing of the filter system. A process for solving the vibration problem based on the modal analysis of the filter system using the commercial finite element software for simulation is therefore proposed. The computed natural frequencies of the system and the vibration data measured on site are assessed based on the resonance effect of the complete system including the piping connected to the filters. Several approaches are proposed to adjust the natural frequencies of the system in such a way that an optimal and a reasonable solution for solving the vibration problem is obtained.
\end{abstract}

\section{Introduction}

A filter system plays an important role in petrochemical plant for removing solid particles and impurities from hydrocarbon oils. In the system, the pipes of various geometrical properties are connected to pumps and filters to transport oil and oil products for treatment $[1,2]$. The temperature of the oil and the oil products in the system can be as high as $200^{\circ} \mathrm{C}$. As the flow and collision of oils in the pipes cause severe vibrations, this led to fatigue and fracture of structural pipe members and connections after being subject to a number of load cycles [3]. As a result, there is a need to examine carefully the most appropriate approach to reducing the unexpected vibrations to prevent the oil leakages and structural member failure in the system.

One of the earliest studies of vibration problems in pipes was conducted by Ashley and Haviland [4]. They used a beam model to establish differential equations for analyzing the pipe motion. On the other hand, Niordson [5] built a shell model to derive differential equations for solving pipe vibration, where the results were found to be comparable to that of Ashley and Haviland [4]. A more complicated study of pipe vibration due to the effect of fluid-structure interaction was carried out based on travelling-wave method by Paidoussis and Denise [6]. Lavooij and Tusseling [7] however derived differential equations using the method of characteristics for solving pipe vibration. For the past 2 decades, the research of pipe vibration has been directed towards the nonlinear analysis, Gorman et al. [8] studied the nonlinear vibration of pipeline system based on a series of simple models comprising pipes of various geometrical properties.

In a petrochemical plant, the filter system is used to filter solid particles and impurities from hydrocarbon oils. The solid particles will clog the sieves after some period of time of operation and thus will affect the flow of oils in pipes. However, it is impossible to replace the sieves or to remove the filter for cleaning while the filter system is in operation. Therefore, a backwashing process is used to clean the sieves of 


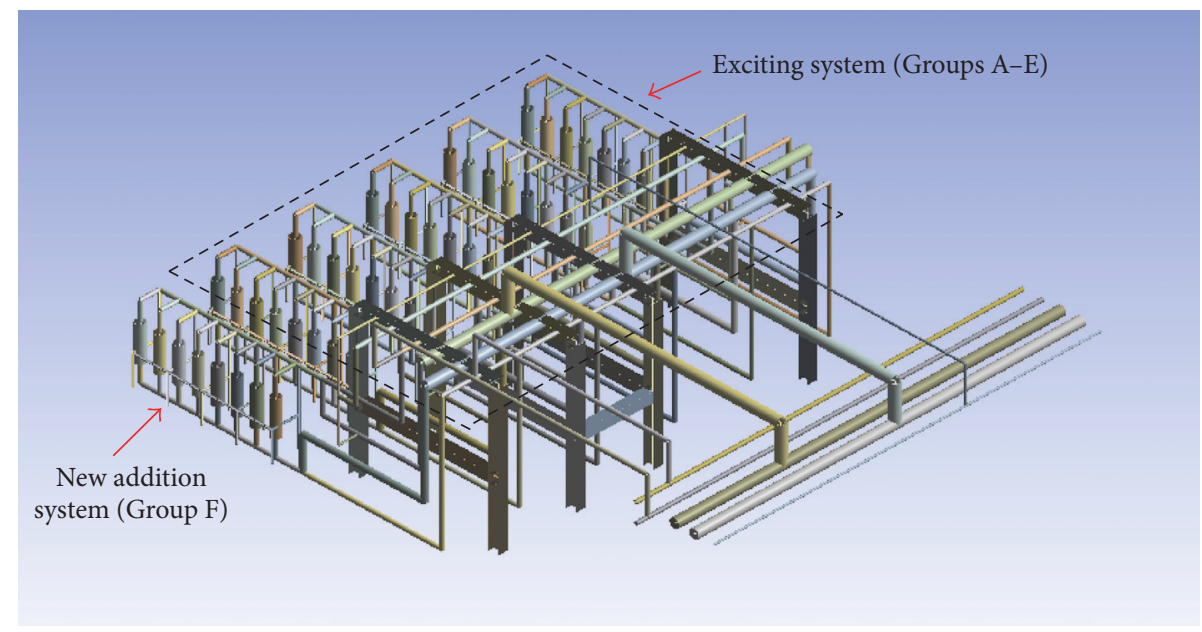

FIgURE 1: The exciting and addition filter system.

the filters. With full particles clogging the sieves and reduced speed of oil flows, a pressure difference between inlet and outlet of the filter system will be generated. The backwashing process will then be activated due to the difference of these working pressures. The backwashing process uses the product oil as a backwashing liquid to flush the filter nets at high pressure so that the solid particles on the sieves could be removed. Once the backwashing liquid hits the filter nets and pipes after it passes through the filters, it causes the filter and the piping system to vibrate. In general, the magnitude of vibration is insignificant and cannot be observed. However, with the increasing production of oil products to meet the demand, the petrochemical company redesigned the system with one additional filter system (Group F) installed next to the existing filters (Groups A to E) as shown in Figure 1. Despite the magnitude of vibration being considered small during the process of backwashing, the oil leakages on pipes and connections however appear after a few years of operation.

An internal stress analysis of the pipes was thereafter performed to rectify the unexpected vibration problem that resulted in fatigue cracking on pipes. The internal stress analysis is a conventional approach commonly adopted for analyzing pipe abnormality under various load conditions based on structural mechanics $[9,10]$. In recent years, Wu et al. [11] carried out a stress analysis model of tunnel pipes under various load combinations. Huang et al. [12] conducted a stress analysis model of elastic laying pipelines in mountainous areas. There is a need to note that the exciting forces of these cases could not easily be determined and measured. On the other hand, the internal forces of the pipelines were typically small that would not result in structural ultimate failure. Most of the structural failures of these pipelines occurring within the elastic limit of materials were actually due to fatigue under load cycles which applied for a period of time. Thus, the stress analysis in this case was not suitable to assess the failure behavior of the filter system. The objective of the current study is to determine a suitable solution with the adjustment of period of vibration to reduce the amplitude of vibration of the system.
In the current study, the filter and the piping system were connected and modelled as a complete system. A modal analysis is conducted to determine the natural frequencies of the system. The exciting forces of the vibration include the pulses of the oil in the pipes and the interaction effect among the oil, the pipes, and the filter system. The response vibration of the complete system due to backwash was measured and presented in a form of time spectrum. The time spectrum was then transformed into the frequency domain by means of fast Fourier transformation (FFT). The FFT spectrum allowed the response frequencies that contributed to vibration to be determined. The peaks of the spectrums presented the frequencies to the natural frequencies of the complete system, where the unexpected vibration is due to the effect of resonance. With the comparison of the FFT spectrums of response vibration to the natural frequencies of the complete system, the region of resonance could be identified [13]. The natural frequencies that cause the resonance and the locations of resonance vibrations could therefore be obtained. As a result, the filter and the piping system could be designed with a specific natural frequency to reduce resonance vibration. Apart from the design of the system to the required natural frequency, the construction time to integrate the new and the existing filter and piping system based on the actual site conditions could also be optimized. In this paper, a method for solving the vibration problem of the complete system with a certain amount of exciting force is summarized and presented.

\section{Modal Analysis}

2.1. Modelling of Filter and the Piping System. The filter and the piping system are modelled using commercial software SolidWorks and ANSYS, as shown in Figure 2, with the modal analysis conducted based on ANSYS.

There are 6 groups of filter and piping system. Each group comprises 8 filter elements. The detail of each filter system is shown in Figure 3. The oil flows through the filter from the bottom of the system from Pipe 1 (inlet) to Pipe 2 (outlet). After the sieves are clogged with solid particles, the backwash 


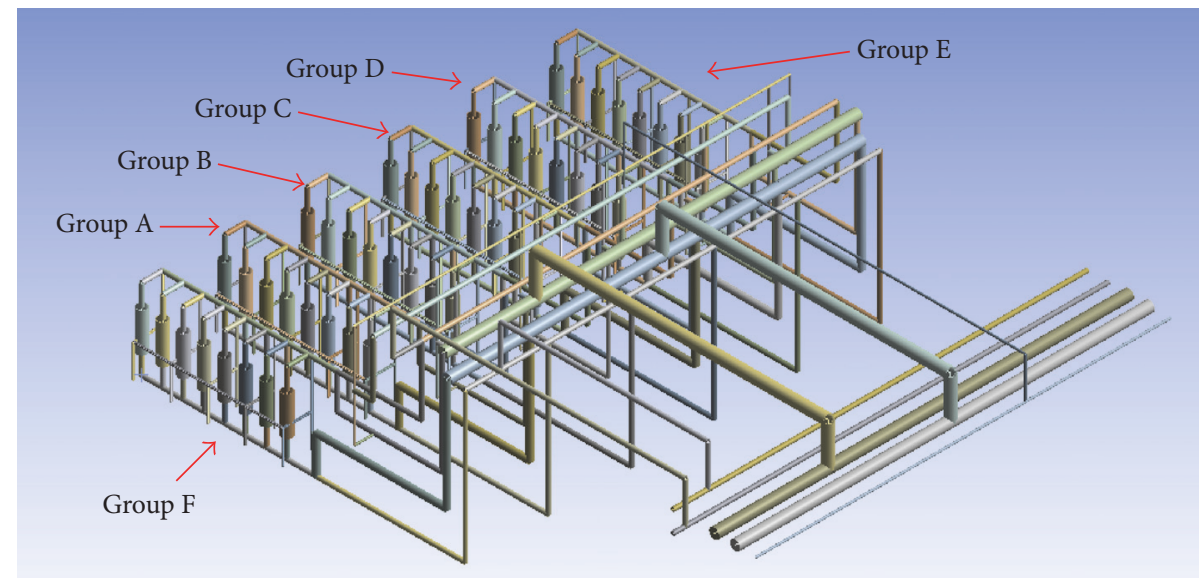

FIgURE 2: A filter and piping system model.

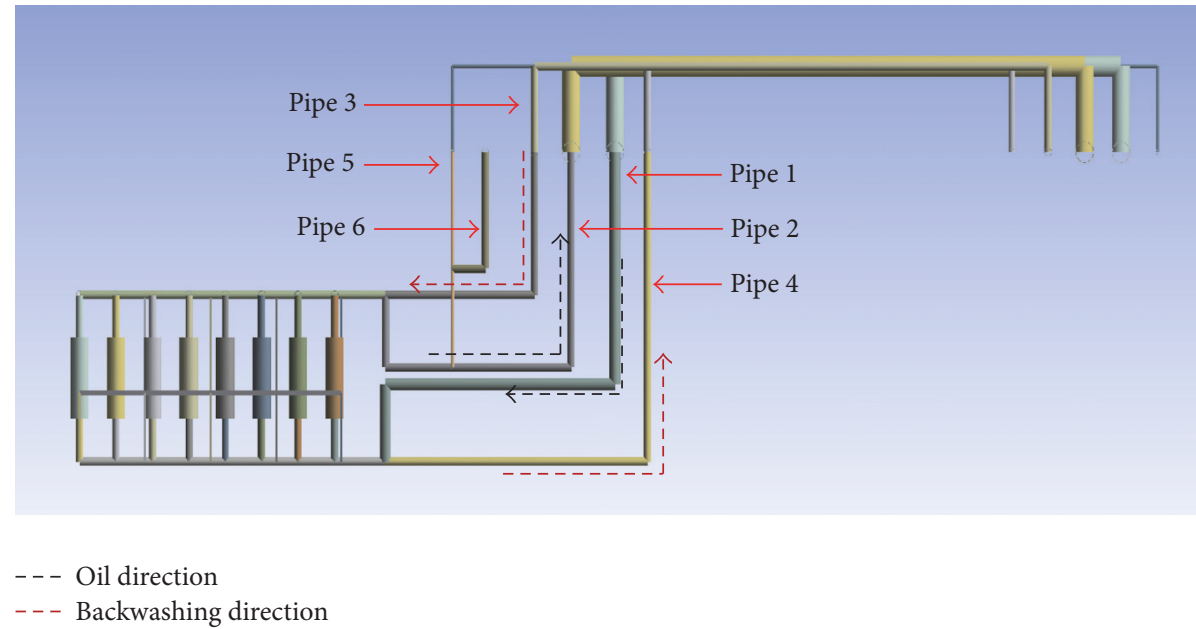

FIGURE 3: Details of each filter system.

operation was activated at a pressure difference between the top and bottom of the filters at $10 \mathrm{~N} / \mathrm{cm}^{2}$ The backwashing oil enters the system from Pipe 3 to Pipe 4 . Pipes 5 and 6 are gas pipes for gas backwashing after the filter nets could not be cleaned using the backwash liquid. These two pipes were usually empty. The 5 pipes were fixed onto a large bracket, which was connected to other brackets on the floor. In the modelling, the brackets were considered fixed on the ground.

The filters were made of stainless steel. Each single filter comprised 28 filter elements with diameter $25 \mathrm{~mm}$ and length $814 \mathrm{~mm}$. The filter elements were threaded into a common flange. The pipes are made of mild steels with geometrical properties as shown in Table 1. Apart from the filters and the pipes, the brackets representing the locations of the constraints would have a significant effect on the natural frequencies of the complete system. These brackets are made of mild steels with cross-sectional properties presented in Figure 4. The complete filter and piping system and their support brackets can be seen in Figure 5 .

2.2. Modal Analysis. The modal analysis was carried out to determine the natural frequencies of the complete system. In
TABLE 1: Outer diameter and thickness of pipes.

\begin{tabular}{lcc}
\hline Pipe number & Outer diameter $(\mathrm{mm})$ & Thickness $(\mathrm{mm})$ \\
\hline$(1)$ & 150 & 7 \\
$(2)$ & 100 & 7 \\
$(3)$ & 100 & 7 \\
$(4)$ & 100 & 7 \\
$(5)$ & 100 & 7 \\
$(6)$ & 50 & 4 \\
\hline
\end{tabular}

the analysis, there were $N$ nodes in the entire system. Each node contained six (6) degrees of freedom with 3 translations and 3 rotations in $x$-, $y$-, and $z$-axis direction [14-16]. A total of $6 \mathrm{~N}$ degrees of freedom were considered in this case. For the complete filter and piping system, it would have $6 \mathrm{~N}$ natural frequencies. The equations of motion can be expressed as follows [14-17]:

$$
\begin{aligned}
{\left[M_{x}\right] x^{\prime \prime}+\left[C_{x}\right] x^{\prime}+\left[K_{x}\right] x } & =\left\{F_{x}\right\}, \\
{\left[M_{y}\right] y^{\prime \prime}+\left[C_{y}\right] y^{\prime}+\left[K_{y}\right] y } & =\left\{F_{y}\right\},
\end{aligned}
$$




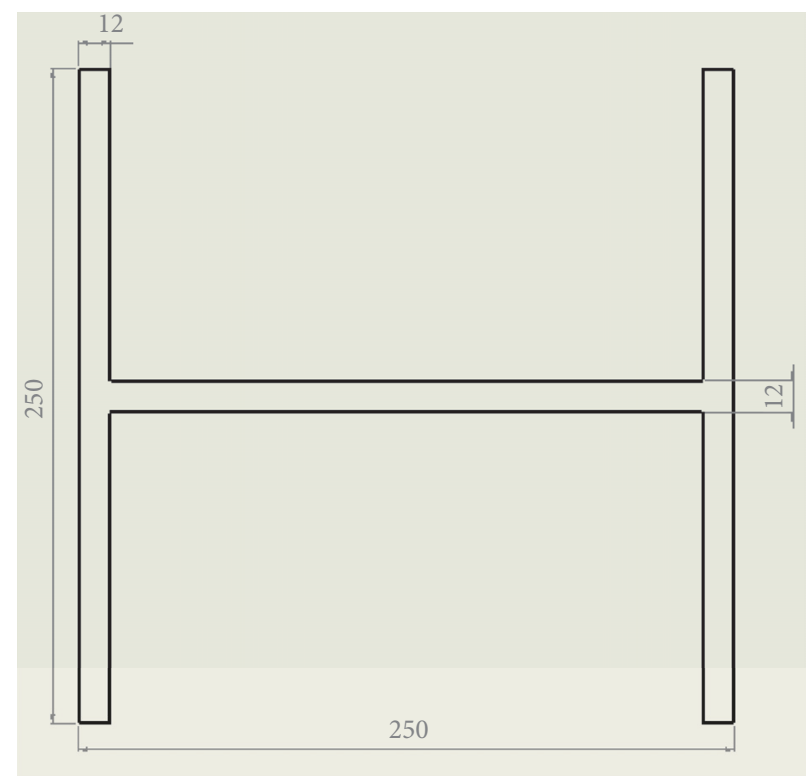

FIgURE 4: Cross section view of bracket (mm).

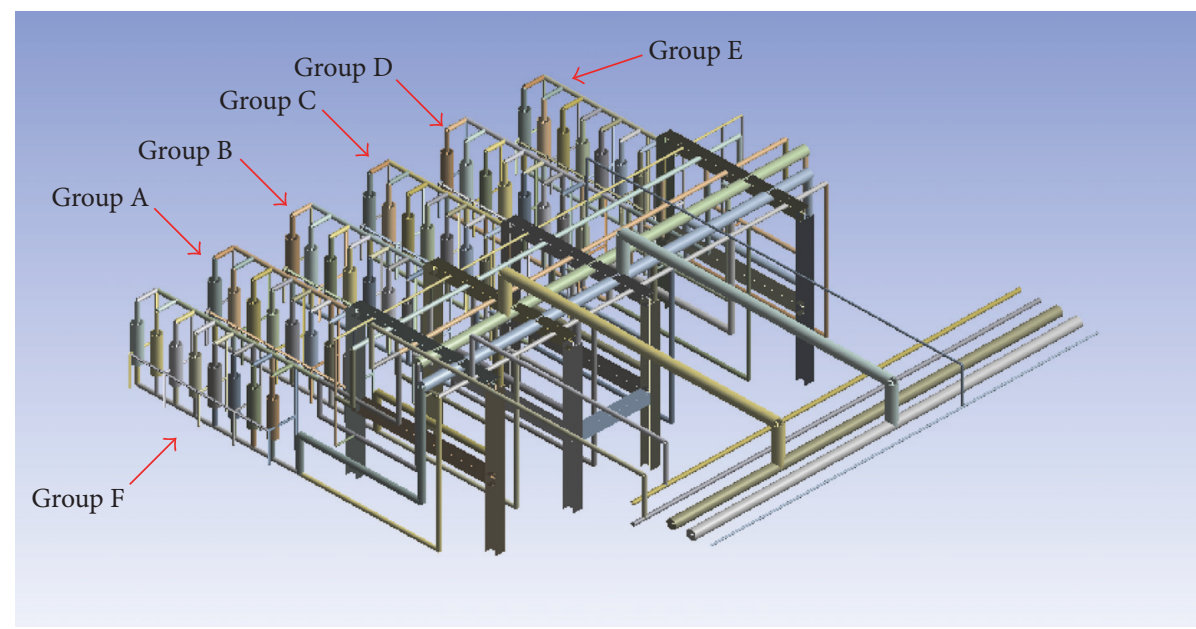

FIGURE 5: A complete filter and piping system.

$$
\begin{aligned}
{\left[M_{z}\right] z^{\prime \prime}+\left[C_{z}\right] z^{\prime}+\left[K_{z}\right] z } & =\left\{F_{z}\right\}, \\
{\left[J_{x x}\right] \theta_{x}^{\prime \prime}+\left[C_{x x}\right] \theta_{x}^{\prime}+\left[K_{x x}\right] \theta_{x} } & =\left\{\text { Moment }_{x}\right\}, \\
{\left[J_{y y}\right] \theta_{y}^{\prime \prime}+\left[C_{y y}\right] \theta_{y}^{\prime}+\left[K_{y y}\right] \theta_{y} } & =\left\{\text { Moment }_{y}\right\}, \\
{\left[J_{z z}\right] \theta_{z}^{\prime \prime}+\left[C_{z z}\right] \theta_{z}^{\prime}+\left[K_{z z}\right] \theta_{z} } & =\left\{\text { Moment }_{z}\right\},
\end{aligned}
$$

where $[M]$ is the mass matrix, $[J]$ is the matrix of tensional moment of inertia, $[C]$ is the matrix of composite damping, $[K]$ is the matrix of system stiffness, $\{F\}$ and $\{$ Moment $\}$ are the exciting force vectors, and $[M],[J],[C]$, and $[K]$ are $N \times N$ matrices.
To obtain the natural frequencies of the system in the modal analysis, the exciting force vector was set to 0 . The matrix representation of transformation after the combination of (1) can be rewritten as follows [1, 14-16]:

$$
\left[\begin{array}{cccccc}
M_{x} & & & & & \\
& M_{y} & & & & \\
& & M_{z} & & & \\
& & & J_{x} & & \\
& & & & & \\
& & & & J_{y} & \\
& & & & & J_{z}
\end{array}\right]\left[\begin{array}{c}
x^{\prime \prime} \\
y^{\prime \prime} \\
z^{\prime \prime} \\
\theta_{x}^{\prime \prime} \\
\theta_{y}^{\prime \prime} \\
\theta_{z}^{\prime \prime}
\end{array}\right]^{T}
$$




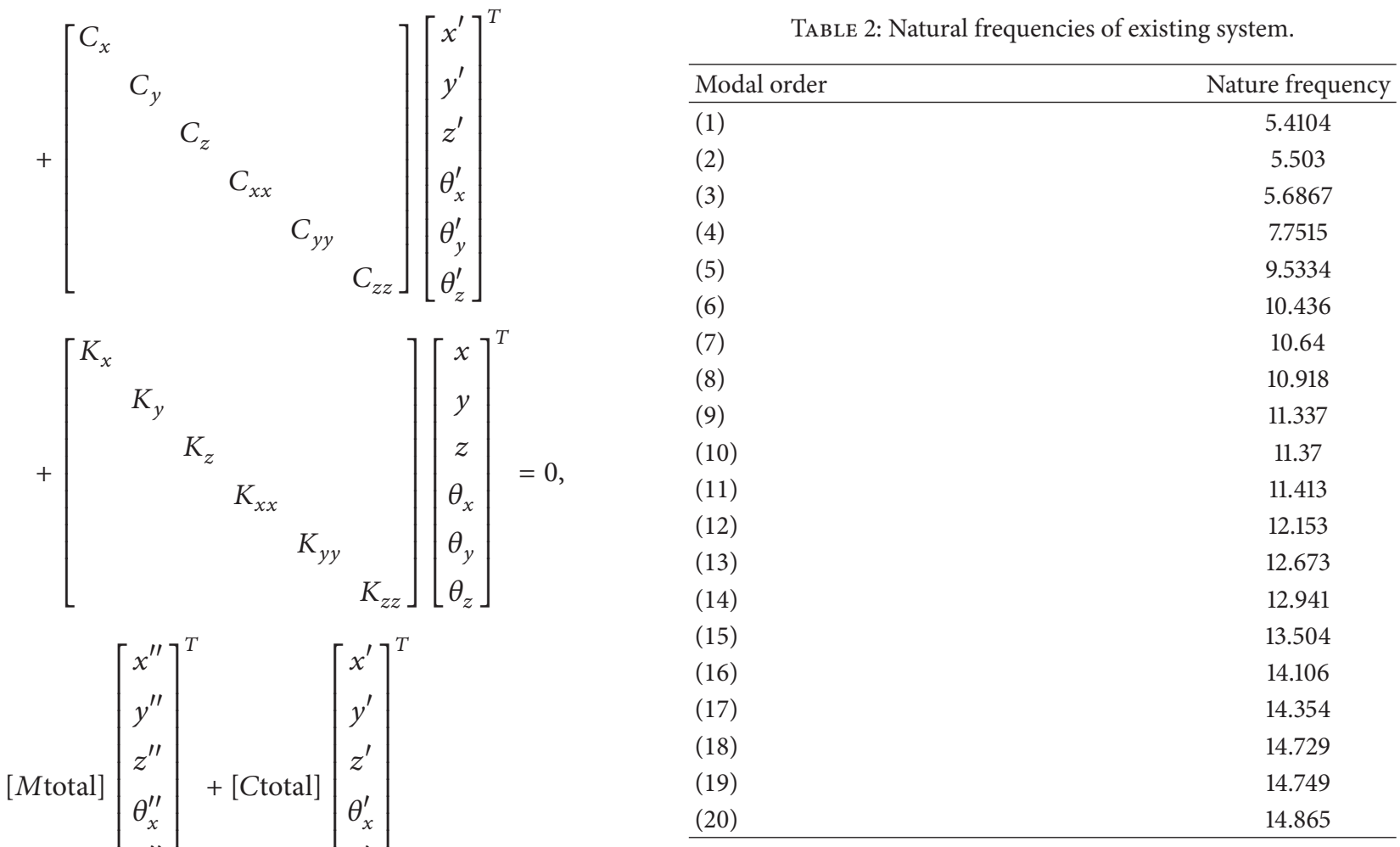

where [Mtotal], [Ctotal], and [Ktotal] are $6 \mathrm{~N} \times 6 \mathrm{~N}$ matrices.

On the basis of equations of motion, the natural frequencies of the system could be obtained from the FEA of the model using the commercial software ANSYS. The natural frequencies of the system below $15 \mathrm{~Hz}$ are listed in Table 2 . The modal orders are arranged in accordance with the natural frequencies of the system. For the free vibration at one of these natural frequencies, a definite relationship between the amplitudes of all the nodes exists. These relationships were known as the mode shapes. If the frequency of exciting force was close to or at one of these natural frequencies, the effect of resonance was considered, and the amplitudes of the nodes were maximum [18]. However, with the consideration of damping in real system structure, the resonance frequencies do not quite match the natural frequencies, and the difference between the two frequencies was actually quite small [14-16]. On the other hand, the amplitudes of the nodes would not increase to infinite. The relationship of the amplitudes of the nodes was close to the mode shape at that natural frequency, 


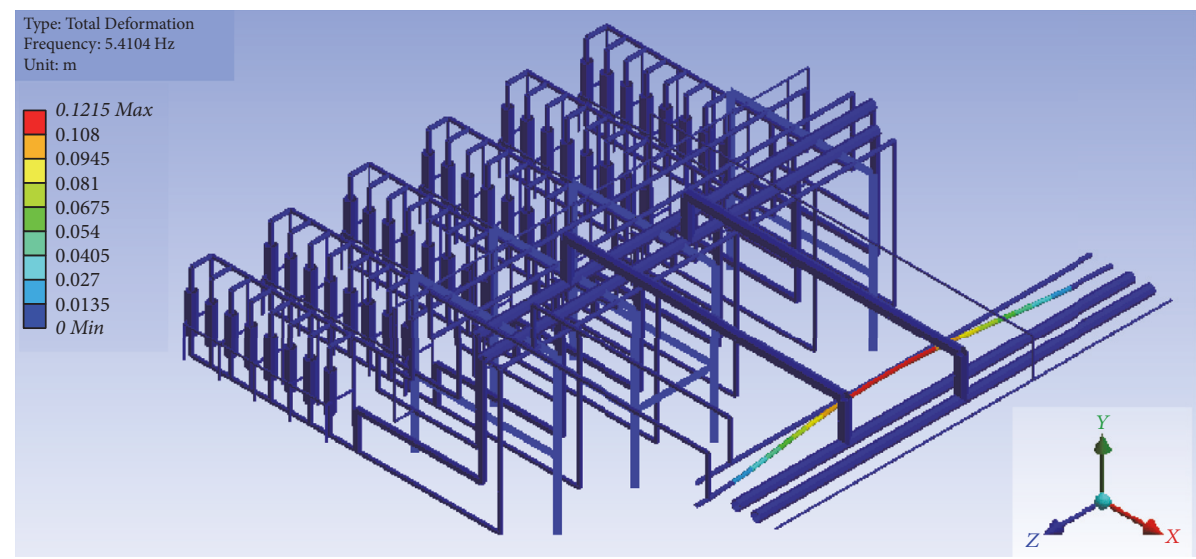

FIGURE 6: Vibration mode of the 1st modal order.

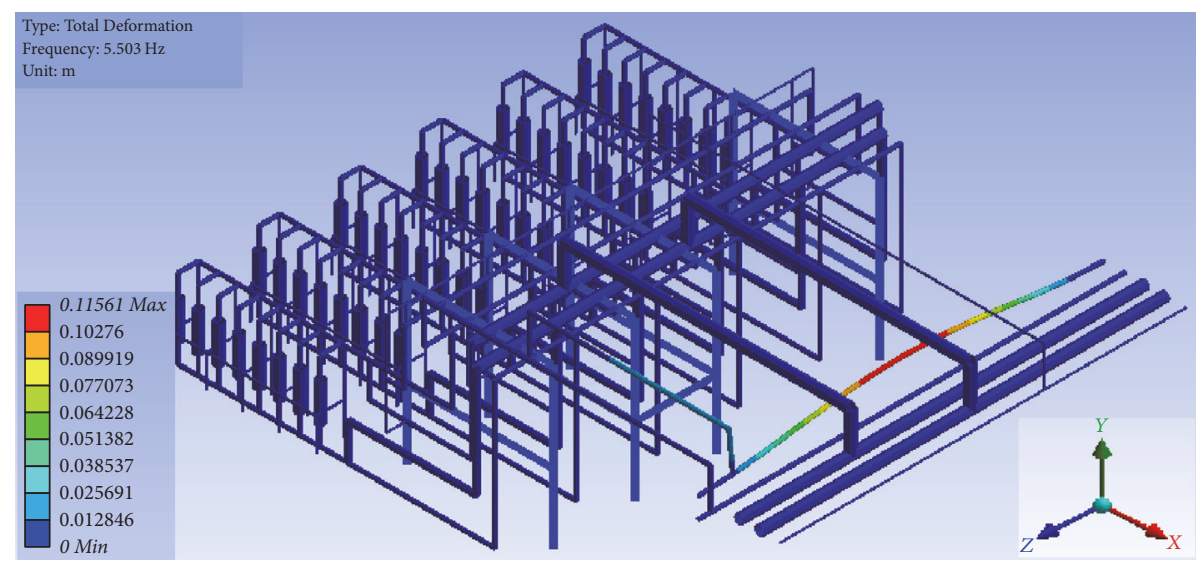

FIgURE 7: Vibration mode of the 2nd modal order.

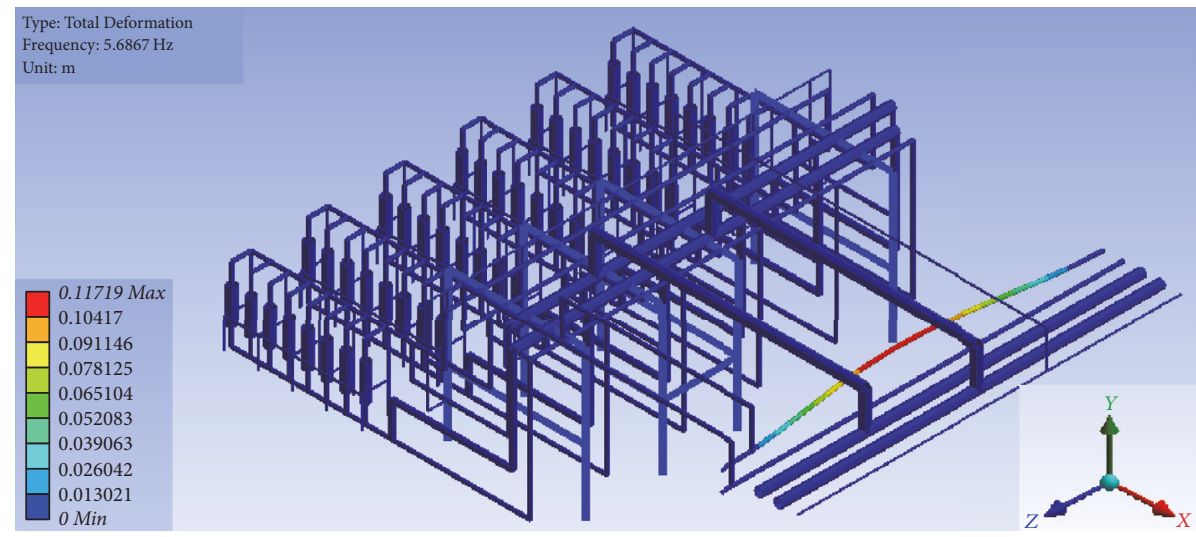

Figure 8: Vibration mode of the 3rd modal order.

problem in this case was to propose a suitable method based on the natural frequency of the system.

\section{Solutions}

From the modal analysis and the vibration measurement, the natural frequencies of the system should be increased above $10 \mathrm{~Hz}$ to avoid the effect of resonance. From the observation of the system performance on site, it can be seen that the vibration actually occurred on free span long pipes without any supports. These pipes were located in the critical vibration of the system. Thus, adding adequate constraints to stiffen these pipes was the first approach to solving the vibration problem. 


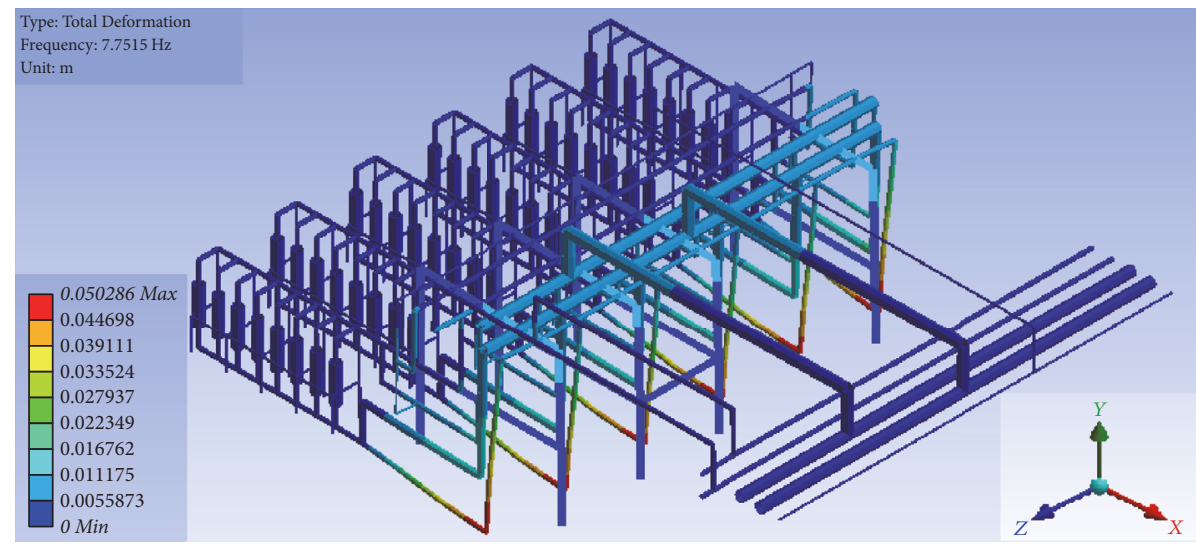

FIGURE 9: Vibration mode of the 4th modal order.

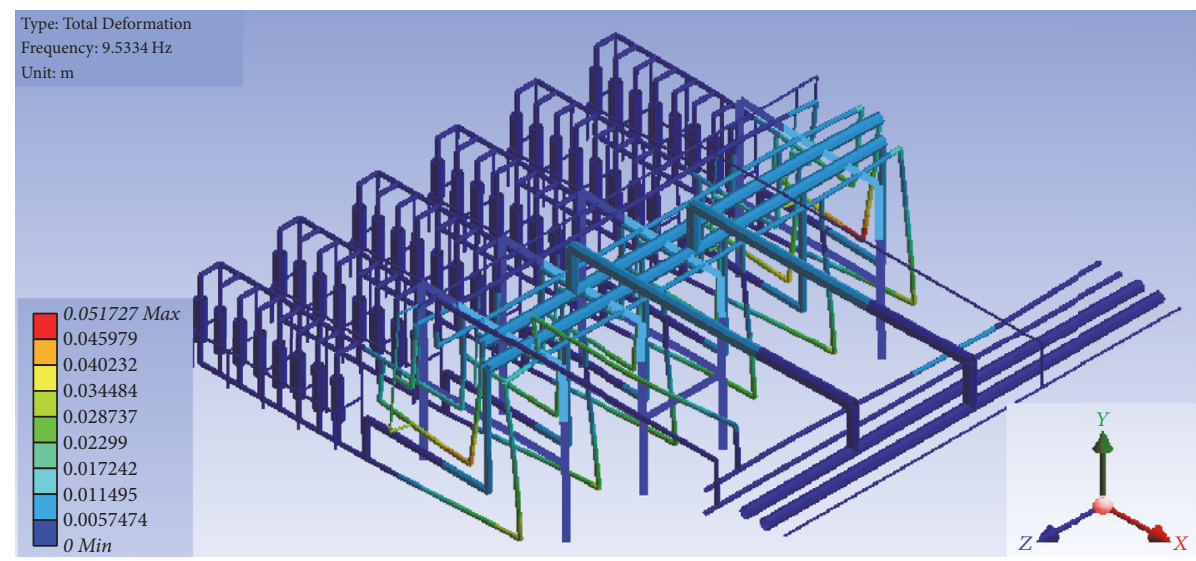

FIGURE 10: Vibration mode of the 5th modal order.

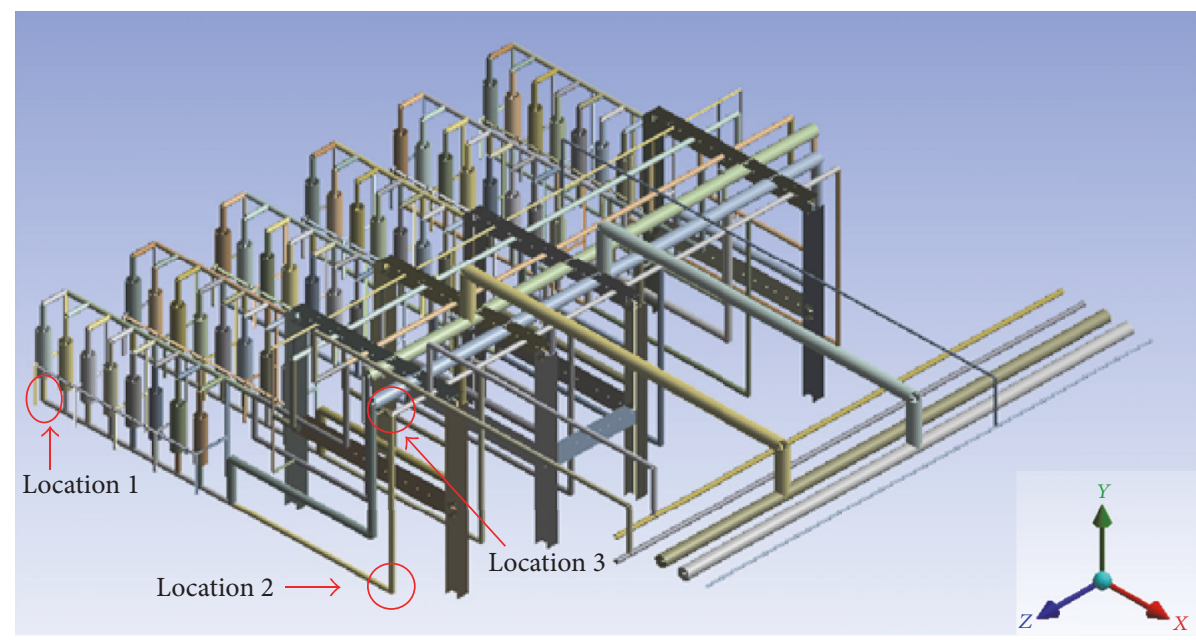

FIGURE 11: Locations of vibration measurement.

4.1. Solution 1. The first approach is to add adequate constraints by connecting the pipes together. This was carried out by connecting the long pipes (Location 4) using $50 \mathrm{~mm}$ diameter pipes. After the pipes are connected, the natural frequencies of the system slightly increase, as shown in Table 3.
However, the vibration of the modal orders with natural frequencies below $10 \mathrm{~Hz}$ no longer occurred at Location 4 . As shown in Figures 16 and 17, the first 2 modes of vibration showed that the vibration locations of the long pipes in the first few modal orders had been shifted. 


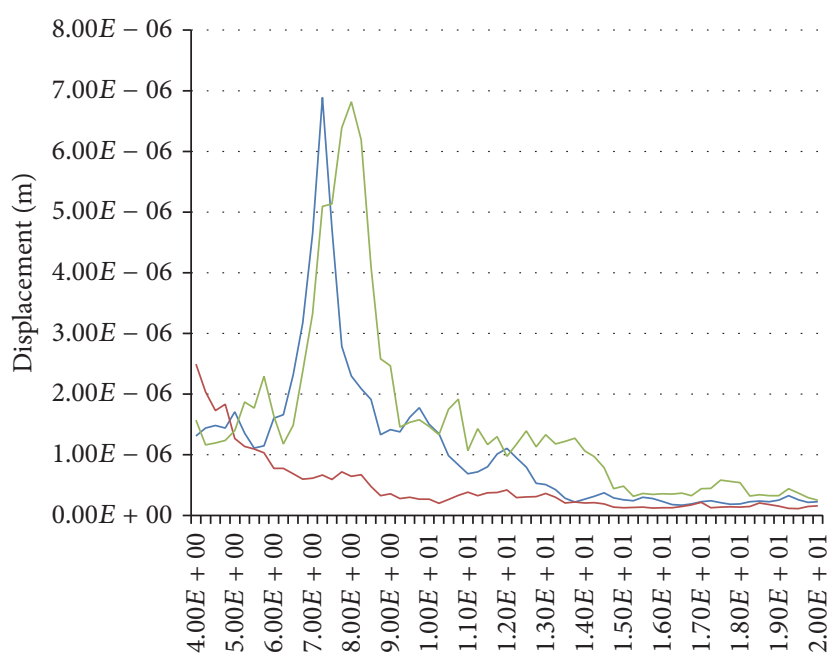

Frequency $(\mathrm{Hz})$

$x$-direction
$-y$-direction
$z$-direction

FIGURE 12: The FFT spectrums of Location 1.

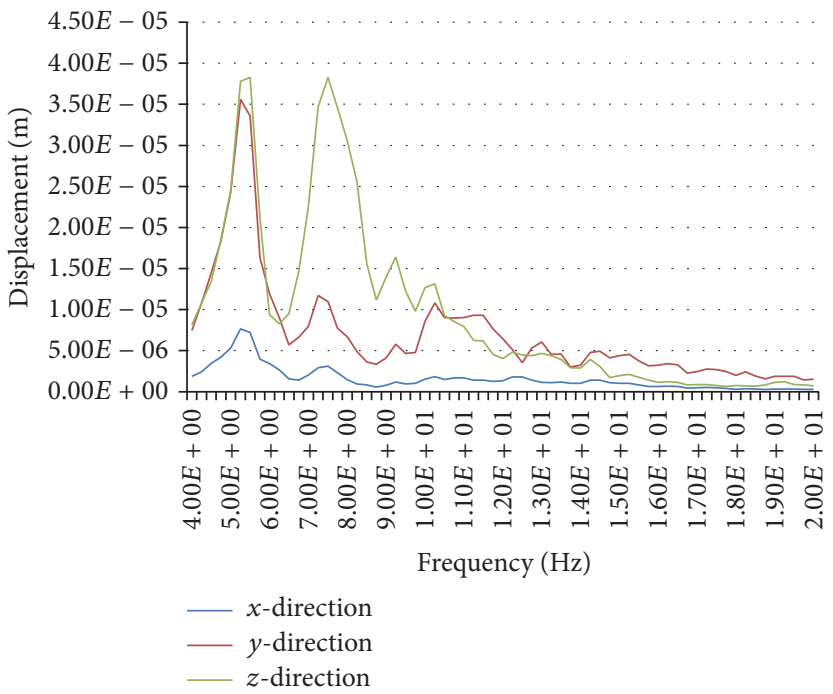

FIgURE 13: The FFT spectrums of Location 2.

The second approach is to connect the long pipes above the passage with 2 additional supports at both sides, as shown in Figure 18. With this arrangement, the natural frequencies of the system are found to increase as shown in Table 4. The vibration locations of the first several modal orders were located along the long pipes in Location 5.

The 3rd approach is to add additional constraints at Location 1 by connecting the long pipes with $50 \mathrm{~mm}$ diameter pipes, as shown in Figure 19. With the additional constraints, all the natural frequencies of the system are found higher than $10 \mathrm{~Hz}$, which is outside the range of resonance (Table 5).

4.2. Solution 2. The process of Solution 2 was identical to that of Solution 1 . The locations of additional constraints are similar to those in Solution 1, as shown in Figure 20. The difference between the 2 solutions was that the constraints of the long pipes in Solution 2 were supported on the floor and other parts of the entire structure system. The natural frequencies of Solution 2 are higher than $10 \mathrm{~Hz}$ (Table 6). The purpose of proposing Solution 2 is to provide an alternative taking into the consideration of construction process of the existing additional filter and piping system.

4.3. Solution 3. For Solution 3, the pipes were connected using spring bumpers to control the increasing stress of the structure system with reduced vibration. The bumpers also absorbed part of the vibration energy. However, the spring bumpers did not increase the natural frequencies of the system effectively. The natural frequencies of the new structure with additional filter and piping system are 


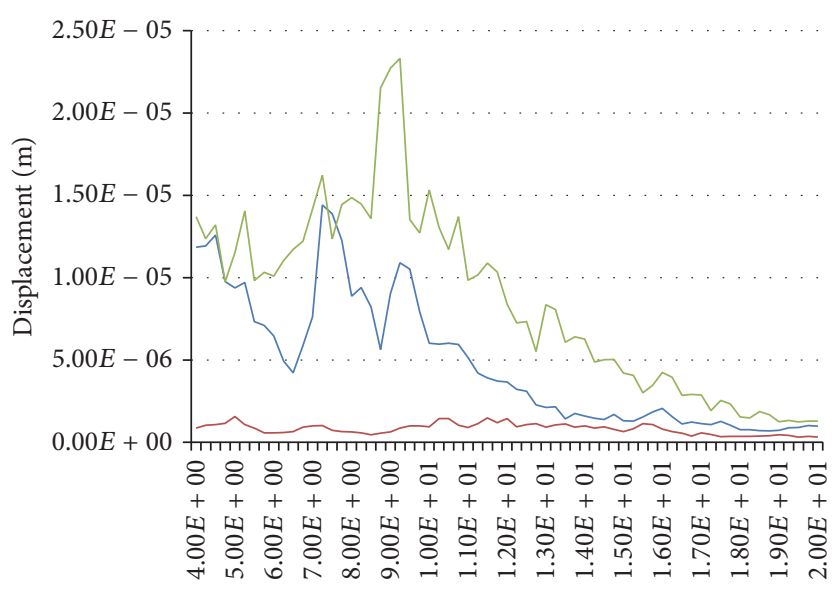

Frequency $(\mathrm{Hz})$

- $x$-direction

$y$-direction

$z$-direction

FIgURE 14: The FFT spectrums of Location 3.

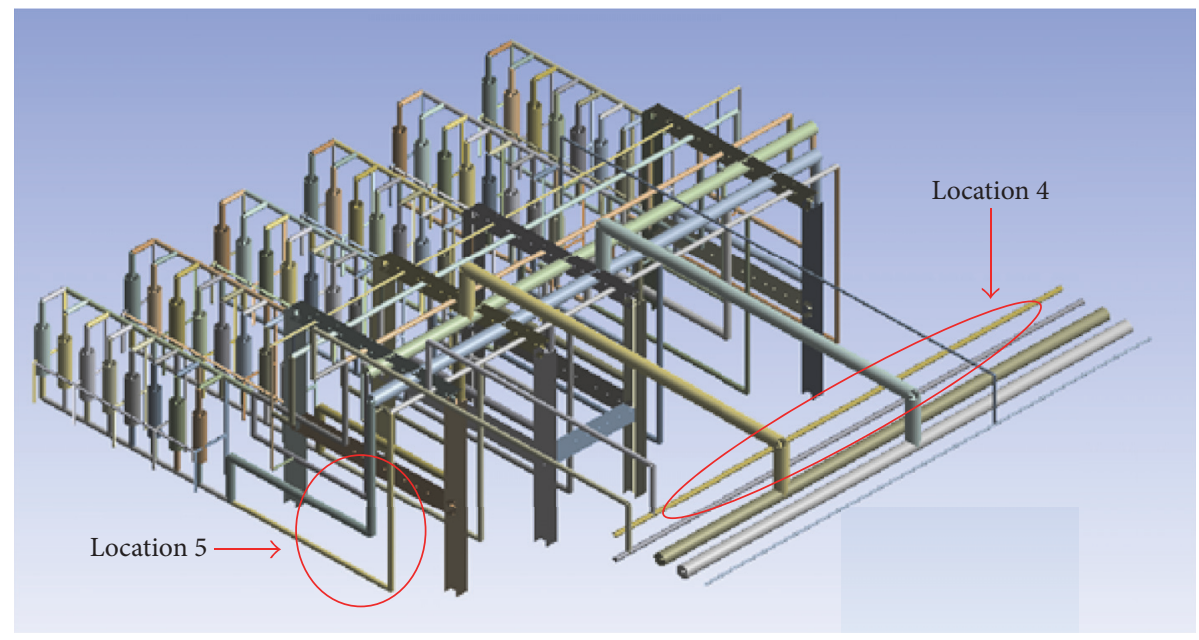

FIGURE 15: Critical locations of vibration.

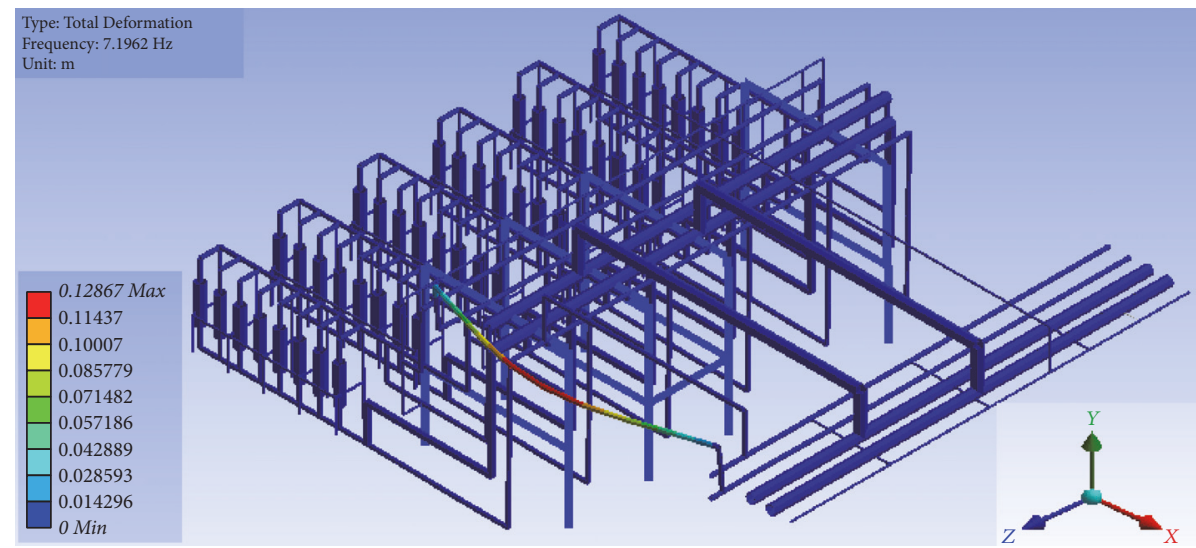

Figure 16: Vibration mode of 1st modal order. 
TABLE 3: Natural frequencies of the system (1st approach).

\begin{tabular}{lc}
\hline Modal order & Natural frequency \\
\hline$(1)$ & 7.1962 \\
$(2)$ & 7.5748 \\
$(3)$ & 9.3668 \\
$(4)$ & 10.426 \\
$(5)$ & 10.643 \\
$(6)$ & 10.918 \\
$(7)$ & 11.347 \\
$(8)$ & 11.413 \\
$(9)$ & 11.72 \\
$(10)$ & 12.312 \\
$(11)$ & 12.822 \\
$(12)$ & 13.144 \\
$(13)$ & 13.517 \\
$(14)$ & 14.292 \\
$(15)$ & 14.715 \\
$(16)$ & 14.751 \\
\hline
\end{tabular}

TABLE 4: Natural frequencies of the system (2nd approach).

\begin{tabular}{lc}
\hline Modal order & Natural frequency \\
\hline$(1)$ & 7.6771 \\
$(2)$ & 9.7916 \\
$(3)$ & 10.425 \\
$(4)$ & 10.558 \\
$(5)$ & 10.759 \\
$(6)$ & 10.918 \\
$(7)$ & 11.349 \\
$(8)$ & 11.414 \\
$(9)$ & 12.327 \\
$(10)$ & 12.834 \\
$(11)$ & 13.139 \\
$(12)$ & 13.261 \\
$(13)$ & 13.551 \\
$(14)$ & 14.308 \\
$(15)$ & 14.401 \\
$(16)$ & 14.715 \\
\hline
\end{tabular}

TABLE 5: Natural frequencies of the system (3rd approach).

\begin{tabular}{lc}
\hline Modal order & Natural frequency \\
\hline$(1)$ & 10.558 \\
$(2)$ & 11.323 \\
$(3)$ & 13.261 \\
$(4)$ & 19.462 \\
$(5)$ & 19.984 \\
$(6)$ & 20.137 \\
$(7)$ & 20.491 \\
$(8)$ & 20.534 \\
$(9)$ & 20.678 \\
$(10)$ & 20.928 \\
\hline
\end{tabular}

TABLE 6: Natural frequencies of the new system.

\begin{tabular}{lc}
\hline Modal order & Natural frequency \\
\hline$(1)$ & 12.156 \\
$(2)$ & 16.414 \\
$(3)$ & 17.301 \\
$(4)$ & 18.083 \\
$(5)$ & 18.367 \\
$(6)$ & 18.444 \\
$(7)$ & 18.541 \\
$(8)$ & 18.636 \\
$(9)$ & 19.723 \\
$(10)$ & 20.321 \\
\hline
\end{tabular}

TABLE 7: Natural frequencies of the new structure.

\begin{tabular}{lc}
\hline Modal order & Natural frequency \\
\hline$(1)$ & 5.6967 \\
$(2)$ & 7.3319 \\
$(3)$ & 8.6949 \\
$(4)$ & 10.512 \\
$(5)$ & 10.534 \\
$(6)$ & 11.01 \\
$(7)$ & 11.048 \\
$(8)$ & 11.428 \\
$(9)$ & 11.488 \\
$(10)$ & 12.241 \\
\hline
\end{tabular}

TABLE 8: Natural frequencies of original and new system.

\begin{tabular}{lcccc}
\hline $\begin{array}{l}\text { Modal } \\
\text { order }\end{array}$ & Original & Solution 1 & Solution 2 & Solution 3 \\
\hline$(1)$ & 5.4104 & 10.558 & 12.156 & 5.6967 \\
$(2)$ & 5.503 & 11.323 & 16.414 & 7.3319 \\
$(3)$ & 5.6867 & 13.261 & 17.301 & 8.6949 \\
$(4)$ & 7.7515 & 19.462 & 18.083 & 10.512 \\
$(5)$ & 9.5334 & 19.984 & 18.367 & 10.534 \\
$(6)$ & 10.436 & 20.137 & 18.444 & 11.01 \\
$(7)$ & 10.64 & 20.491 & 18.541 & 11.048 \\
$(8)$ & 10.918 & 20.534 & 18.636 & 11.428 \\
$(9)$ & 11.337 & 20.678 & 19.723 & 11.488 \\
$(10)$ & 11.37 & 20.928 & 20.321 & 12.241 \\
\hline
\end{tabular}

listed in Table 7. As each spring bumper is only effective in one direction, more constraints would be needed in this solution, which led to a longer construction time and a more complicated construction process.

4.4. Optimal Solution. The natural frequencies of Solutions 1,2 , and 3 are summarized in Table 8. Unlike Solution 3, both Solutions 1 and 2 increase the natural frequencies to a level higher than $10 \mathrm{~Hz}$. Solution 3 could not achieve the same effect even with additional constraints. It can therefore be concluded that a fixed constraint would perform better in changing the natural frequencies than an elastic restraint. 


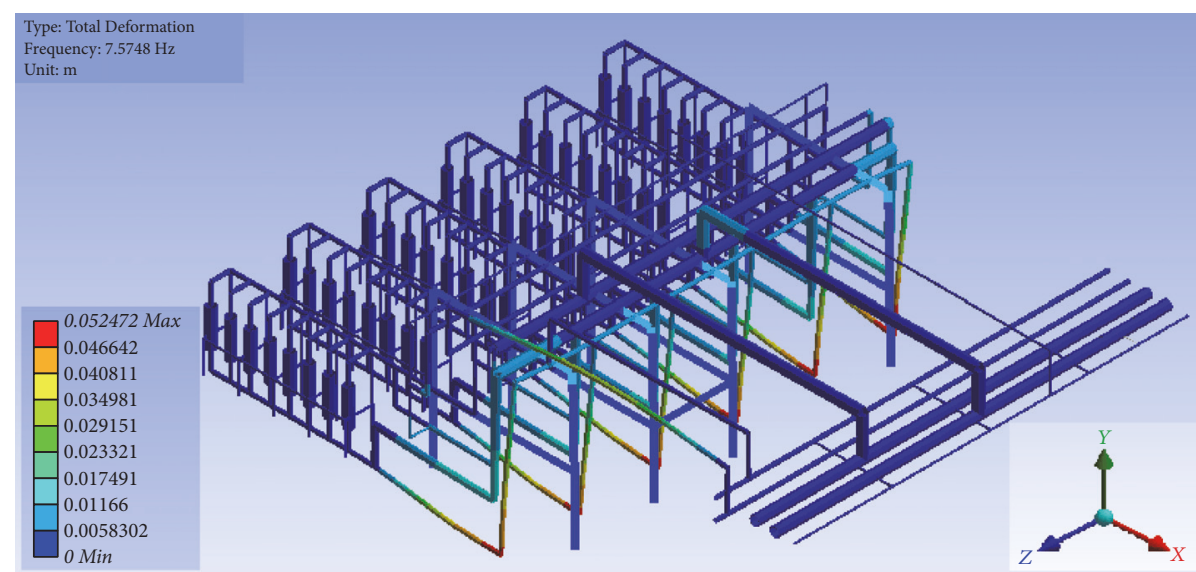

FIGURE 17: Vibration mode of 2nd modal order.

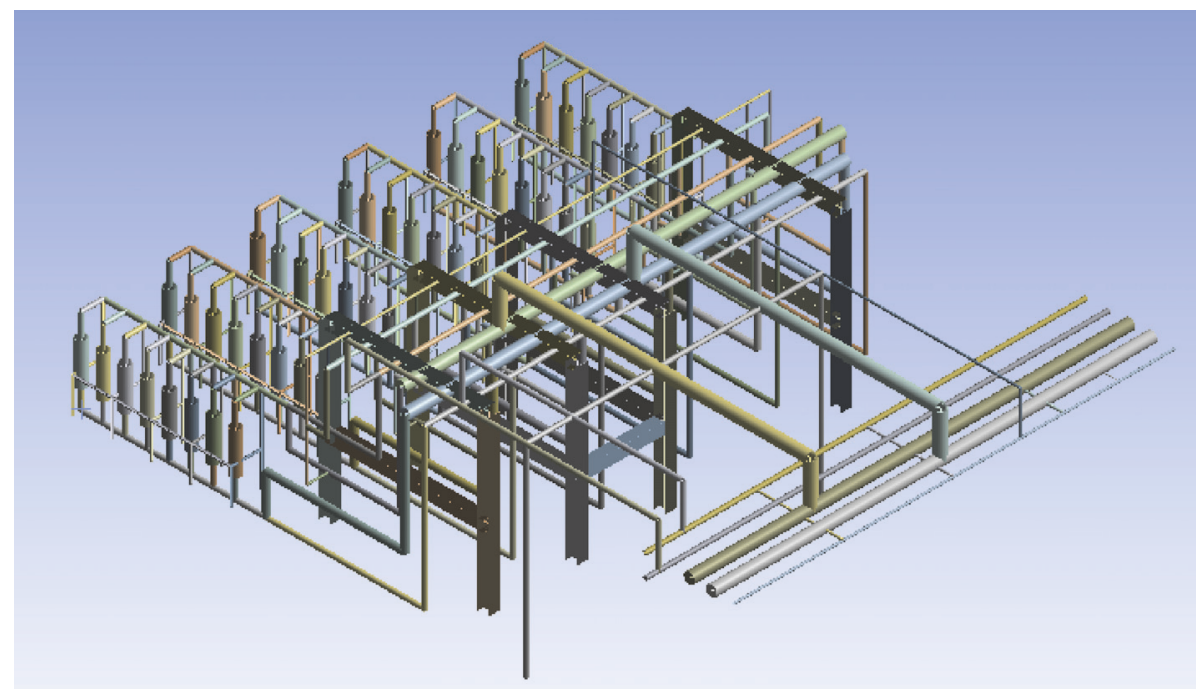

Figure 18: Additional constraints (2nd approach).

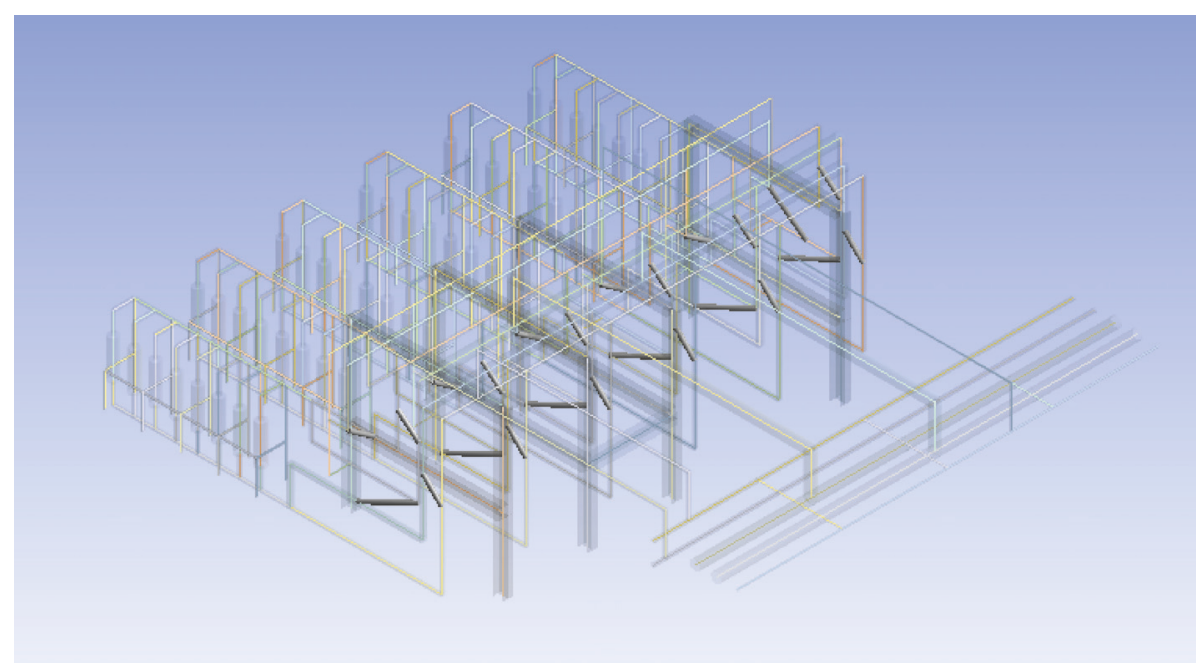

FIGURE 19: Additional constraints (3rd approach). 


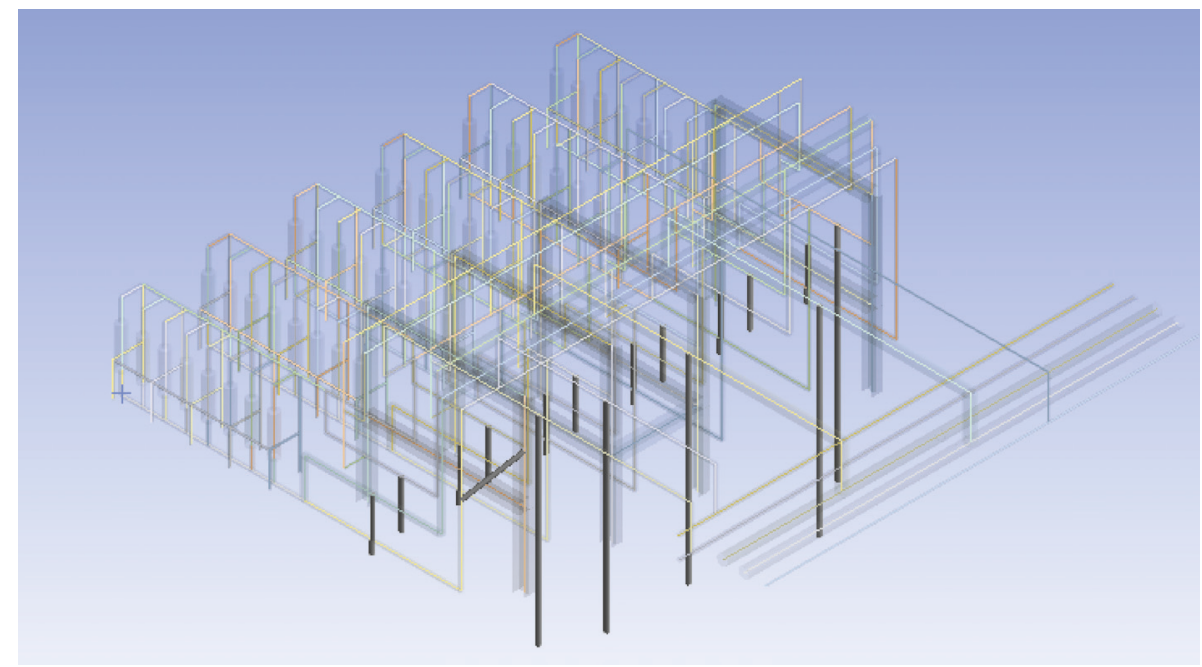

Figure 20: Additional constraints in Solution 2.

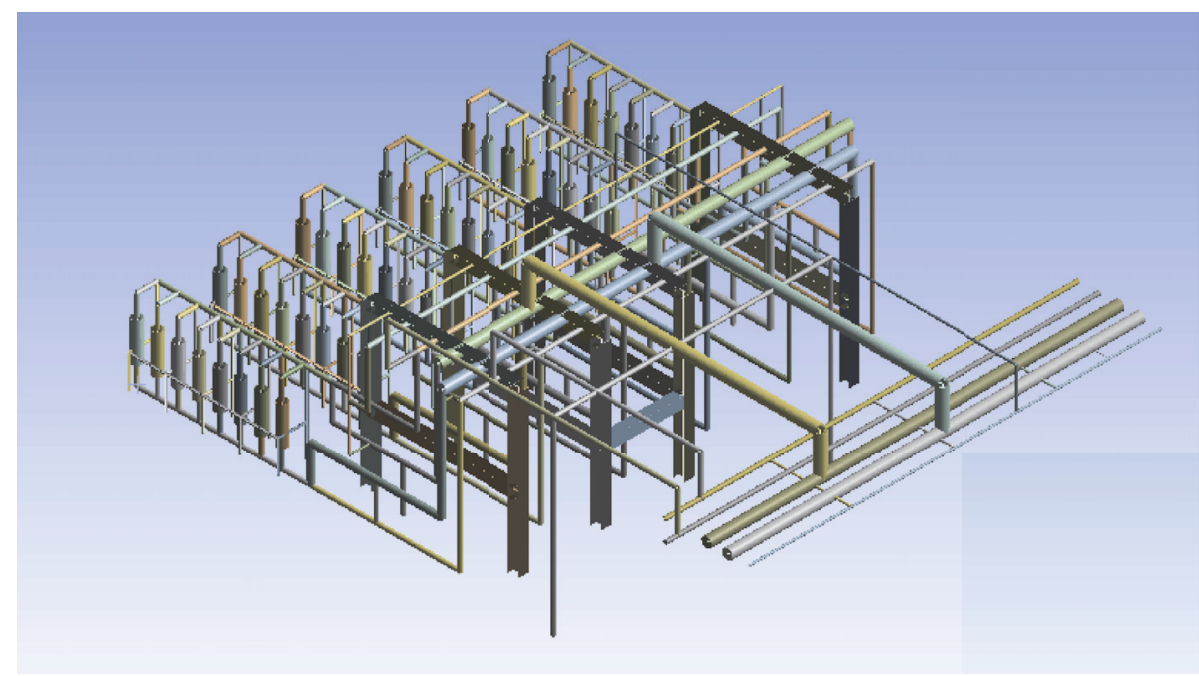

FIGURE 21: Structural modification.

Further, an elastic restraint such as a spring bumper was only effective in one direction, which requires a more complex construction and a longer construction time. Based on the simulation results, Solution 1 or 2 should be chosen as the optimal solution. The choice of a suitable solution would depend on the kind of constraints and the requirement on site.

4.5. Structural Modification. The structural modification combined Solutions 1 and 2 based on site condition. The long pipes in Location 4 in Solution 1 were connected with each other. The pipes above were supported and fixed onto a large bracket. As the pipes in Location 5 were very close to the foundation of the system, they were fixed to the short brackets on the floor (Figure 21). A vibration measurement of Location 2 was carried out to inspect the effect of the modification of the system. The FFT spectrums are plotted as shown in Figure 22. The peaks of the spectrums did not exist and the displacement of vibrations was reduced. Thus by changing the natural frequencies, the system could be made outside the region of resonance.

\section{Conclusion}

The current study provides three (3) solutions to reduce the unexpected vibration of a backwashing system of a petrochemical plant. The comparison of the results between the site measurement and the modal analysis suggested that the cause of vibration of the system can be speculated as being resonance.

All the 3 proposed solutions will result in the increment of natural frequencies of the system. However, from the simulation, it can be seen that the fixed constraint is more effective than the elastic restraint in changing the natural frequencies to reduce the vibration of the structure system. The proposed Solution 3, with spring bumpers to constrain the pipes, has a longer construction time and is less effective in increasing the natural frequencies. With the consideration 


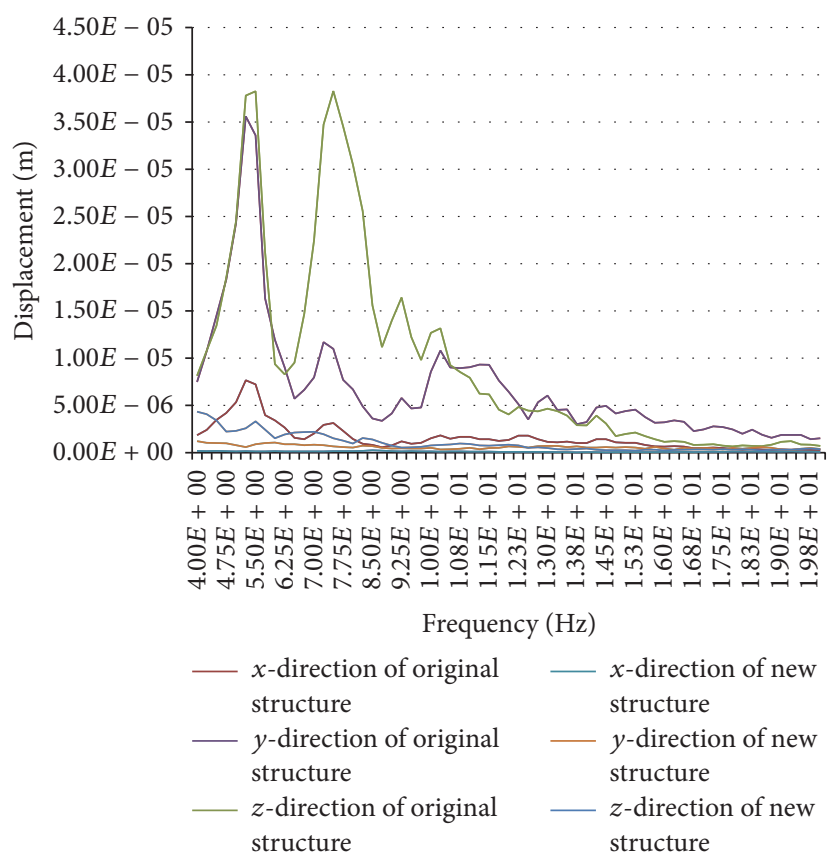

FIGURE 22: The FFT spectrums of original and new structure at Location 2.

of analysis results and the site conditions, Solutions 1 and 2 are the optimal solutions for solving the resonance problem of backwashing system. The combined Solutions 1 and 2 provide the best solution based on the site situation.

\section{Conflicts of Interest}

The authors declare that they have no conflicts of interest.

\section{References}

[1] J. Tian, C. Yuan, L. Yang, C. Wu, G. Liu, and Z. Yang, "The vibration analysis model of pipeline under the action of gas pressure pulsation coupling," Engineering Failure Analysis, vol. 66, pp. 328-340, 2016.

[2] H. Lu, K. Huang, and S. Wu, "Vibration and stress analyses of positive displacement pump pipeline systems in oil transportation stations," Journal of Pipeline Systems Engineering and Practice, vol. 7, no. 1, Article ID 05015002, 2016.

[3] J. C. Wachel, F. R. Szenasi, and S. C. Denison, "Analysis of vibration and failure problems in reciprocating triplex pumps for oil pipelines," in Proceedings of the Proc., Energy-Sources and Technology Conf. and Exhibition, pp. 1-8, Dallas, TX, USA, 1985.

[4] H. Ashley and G. Haviland, "Bending vibrations of a pipe line containing flowing fluid," Journal of Applied Mechanics, vol. 17, no. 3, pp. 229-232, 1950.

[5] F. I. Niordson, Vibrations of a Cylindrical Tube Containing Flowing Fluid, Transactions of the Royal Institute of Technology, Stockholm, Sweden, Elanders Boktr, Stockholm,Sweden, 1953.

[6] M. P. Païdoussis and J.-P. Denise, "Flutter of cylindrical shells conveying fluid," Journal of Sound and Vibration, vol. 16, no. 3, pp. 459-461, 1971.

[7] C. S. W. Lavooij and A. S. Tusseling, "Fluid-structure interaction in liquid-filled piping systems," Journal of Fluids and Structures, vol. 5, no. 5, pp. 573-595, 1991.
[8] D. G. Gorman, J. M. Reese, and Y. L. Zhang, "Vibration of a flexible pipe conveying viscous pulsating fluid flow," Journal of Sound and Vibration, vol. 230, no. 2, pp. 379-392, 2000.

[9] R. K. Watkins and L. R. Anderson, Structural Mechanics of Buried Pipes, CRC Press, London, UK, 1999.

[10] G. Q. Yu and Z. H. Lv, "Load calculation and analysis of heatingpipeline based on elastic center method," GasHeat, vol. 28, no. 12, pp. 20-24, 2008.

[11] X. N. Wu, Y. Xian, K. Huang, M. L. Hu, and B. J. Shang, "Thestress analysis of tunnel gas pipeline underoperating situation," Oil GasStorage Trans, vol. 31, no. 12, pp. 927-930, 2012.

[12] K. Huang, S. J. Wu, H. F. Lu, Y. Xian, and Q. W. Su, "Stressanalysis of the pipeline laid along the slope," Natural Gas Oil, vol. 30, no. 4, pp. 1-4, 2012.

[13] Z. J. Wang and Y. Zhou, "Vortex-induced vibration characteristics of an elastic square cylinder on fixed supports," Journal of Fluids Engineering, Transactions of the ASME, vol. 127, no. 2, pp. 241-249, 2005

[14] W. T. Thomson, Free Vibration. Theory of Vibration with Applications, Allen Unwin, London, UK, 2nd edition, 1981.

[15] W. T. Thomson, Two Degrees of Freedom. Theory of Vibration with Applications, Allen Unwin, London, UK, 2nd edition, 1981.

[16] W. T. Thomson, Properties of Vibration Systems. Theory of Vibration with Applications, Allen Unwin, London, UK, 2nd edition, 1981.

[17] S. Gao, L. Wen, and W. Liao, "Application of dynamic characteristic analysis technology for stator end-winding of large capacity turbo-generator," in Proceedings of the 3rd International Symposium on Intelligent Information Technology Application, (IITA '09), pp. 669-671, November 2009.

[18] M. R. Kruntcheva, "Acoustic-structural resonances of thinwalled structure - Gas systems," Journal of Vibration and Acoustics, Transactions of the ASME, vol. 128, no. 6, pp. 722-731, 2006. 


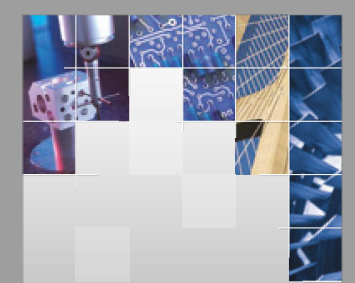

\section{Enfincering}
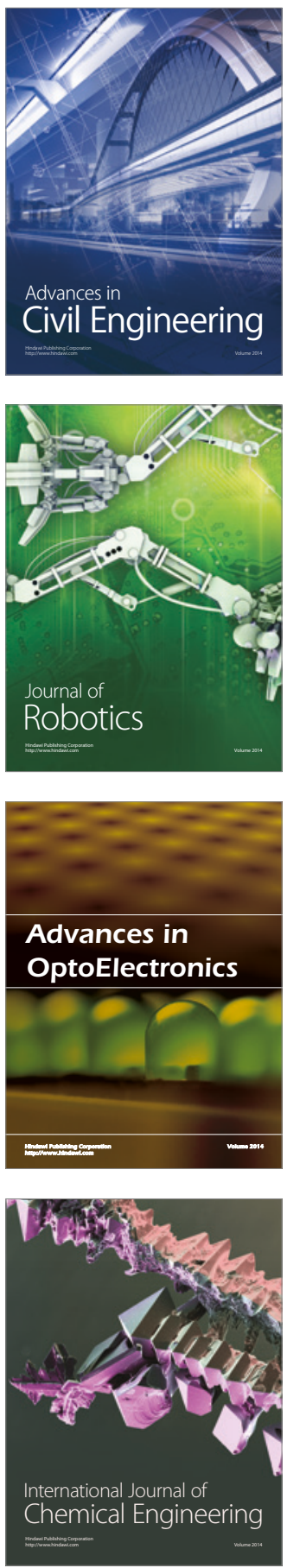

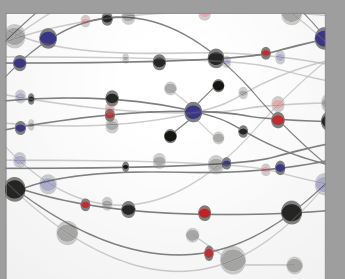

The Scientific World Journal

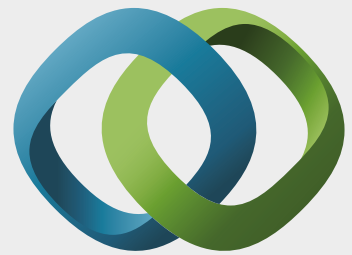

\section{Hindawi}

Submit your manuscripts at

https://www.hindawi.com
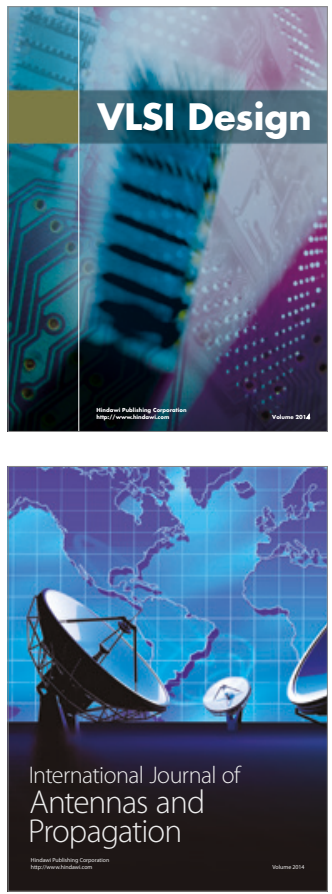

\section{Rotating}

Machinery
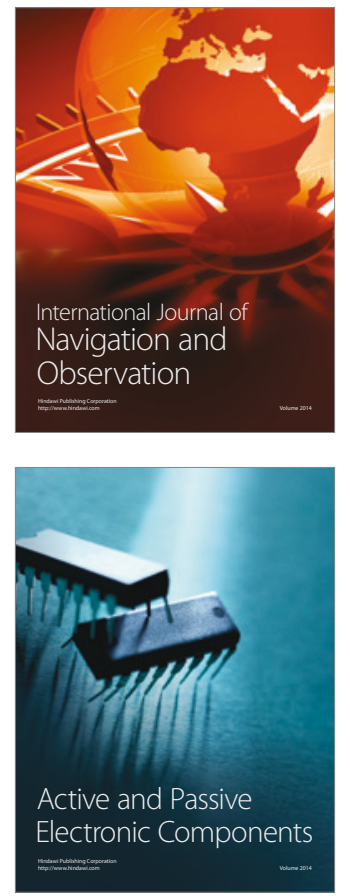
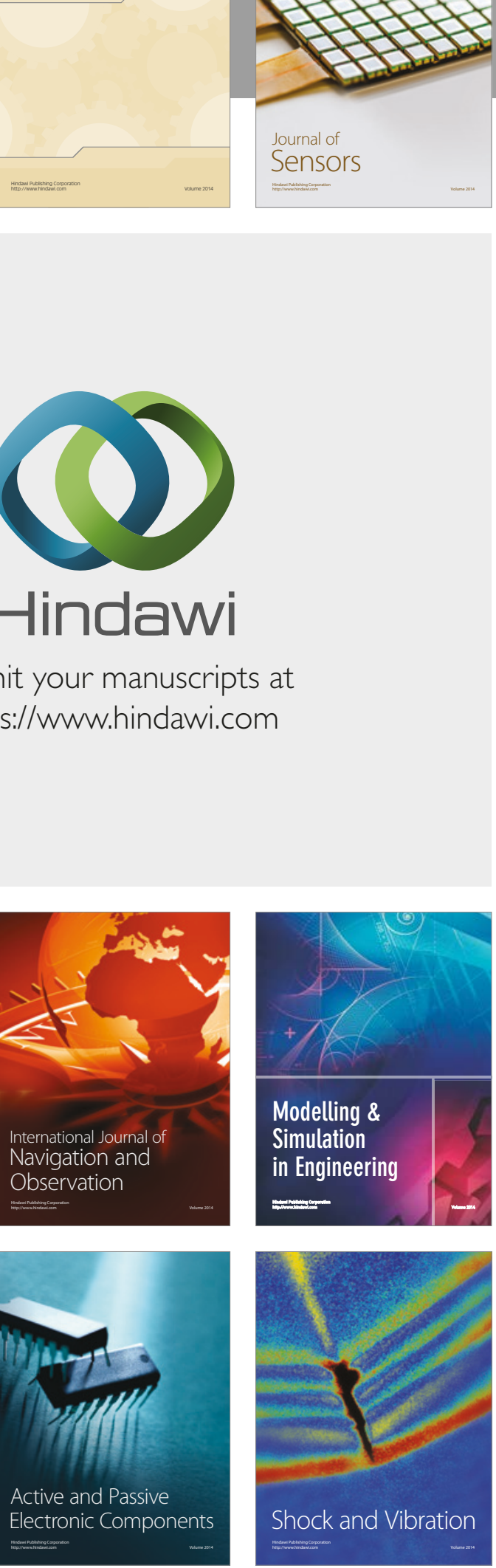
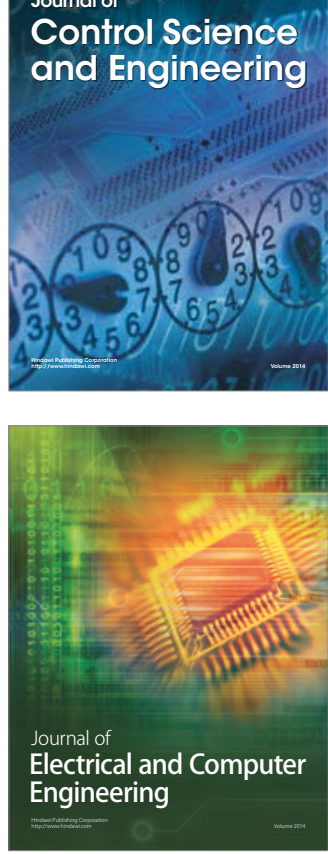

Distributed

Journal of

Control Science

and Engineering
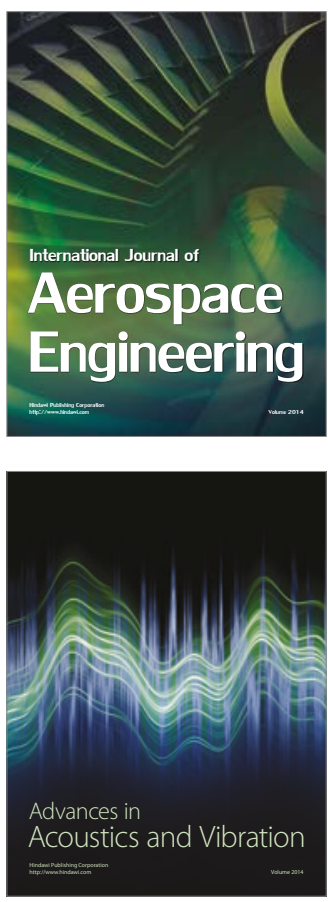

Sensor Networks 